\title{
Comparison of an alveolar expansion technique and buccal guttering technique in the extraction of mandibular third molar. A pilot study
}

\author{
Babatunde O. Akinbami, Lucky I. Ofomala
}

University of Port Harcourt Teaching Hospital, Port Harcourt, Nigeria.

Email: akinbamzy3@yahoo.com; ofomala@yahoo.com

Received 30 May 2011; revised 4 July 2011; accepted 2 July 2011.

\begin{abstract}
Background: The over-ambitious use of surgical drills for almost every case of third molar impaction is on the increase in most established oral surgery centers. The purpose of this study was to assess and compare the severity of post operative symptoms of swelling and pain that accompany the use of surgical drill in the buccal guttering technique and the non application of drill in an alveolar expansion technique. Methods: Consecutive patients with bilateral impacted lower third molars not associated with pericoronitis were included in the study, a total of 10 patients were included in the study. Extraction of both impacted third molars was done consecutively on the same day under local anaesthesia. Post operative morbidities that were assessed clinically are swelling and pain. Results: A total of $\mathbf{1 0}$ patients, $\mathbf{7 0 \%}$ were females and males were $30 \%$. Age range was 27 - 35 yrs. Out of the eight patients that had the two different techniques, 7 preferred the use of the alveolar expansion technique in which drill was not used. There were statistically significant differences in swellings between these two techniques, $(p<0.01)$ but no statistically significant differences in pain $(p>$ 0.01). Conclusions: To avoid excessive swelling and pain from over-ambitious cutting of soft tissues and drilling of bone, alveolar expansion technique should be considered first in patients with less dense bone.
\end{abstract}

Keywords: Alveolar Expansion Technique; Mandibular; Third Molar; Extraction

\section{INTRODUCTION}

Extraction of any upright tooth can be routinely done with the use of tooth extraction forceps especially when the crown is intact. In cases of insufficient crown sub- stance, crown/root fracture, and impaction, appropriate elevators may have to be applied with or without the removal of surrounding alveolar bone [1]. Bone around impacted third molar is usually dense and further reinforced by the external oblique ridge. This requires the use of cutting drills in buccal guttering technique or osteotomies in lingual split technique to remove bone around the impacted, in other to allow manipulation of the tooth out of the socket [2].

These techniques may occasionally not suffice without tooth division technique using very sharp cutting drills [3]. Drilling or cutting of the surrounding bone or tooth is made possible by exposure through incision and reflection of the overlying mucosa. Despite the fact that these bone removing techniques creates space for the tooth to be removed, the vibration and friction caused by the rotating drills and the hits/taps of the osteotomies and mallet are most times very inconvenient and unbearable for many patients treated under local anaesthesia. In addition, the attending post-operative swelling, trismus and pain as well as possible injuries to the contiguous nerves affect the activities of the patients significantly.

The use of graded sizes of Coupé land elevators alone to create space between the tooth and bone, to remove some bone around the tooth with carefully guided pressure and subsequent elevation of the impacted tooth has been of great benefit to some patients by minimizing the post-operative morbidities. The aim of this study was to compare the degree of post-operative morbidity in the alveolar expansion technique and buccal guttering technique of the third molar extraction.

\section{METHODS AND PATIENTS}

The study was a prospective, cross over and comparative analysis of the severity of the post-operative morbidities of two techniques of extraction of mandibular third molar. These are the buccal guttering technique and an al- 
veolar expansion technique. The study was conducted in the department of Oral and Maxillofacial Surgery, University of Port Harcourt Teaching Hospital, Port Harcourt, Nigeria. Ethical clearance was obtained from the hospital's ethics and research committee and patients gave their informed consent permitting the carrying out of the procedures and participation in the conduction of the research. Consecutive patients with bilateral impacted lower third molar not associated with pericoronitis were included and patients with local pathologies were excluded.

A total of 10 patients were included in the study. Five patients were in the first group and they had guttering technique done on the right and alveolar expansion technique on the left side. Three patients were in the second group and they had alveolar expansion technique on the right side and buccal guttering technique on the left side. The last 2 cases served as control to compare similar technique in a patient. One control had buccal guttering technique on both sides and the second had alveolar expansion technique on both sides.

Periapical x-rays were taken to assess the root configuration, proximity to the inferior alveolar neurovascular bundle and impaction against the second molar. All the patients had similar type, class and depth of impaction on either side according to the Pederson's classification. Extraction of both impacted third molars was done consecutively on the same day under local anaesthesia (2\% lidocaine $1.8 \mathrm{mls} ; 1: 80,000$ aldrenaline). Post operative morbidities that were assessed clinically are swelling and pain. Subjective assessments also entailed asking for the opinion of the patients on their preferred choice of technique.

\section{Alveolar Expansion Technique Procedure}

With the partly exposed tooth, a $1 \mathrm{~cm}$ long incision was made on the overlying gum distal or mesial to crown. Periosteal elevator was used to reflect soft tissue without stripping of the gums from the buccal surface.

The smallest size of Coupé land chisel is applied with moderate pressure, using the palmer pad of the distal portion of the first finger to guide the tip and prevent the elevator from slipping, the instrument was maneuvered in between the tooth and the surrounding bone in other to create space by chiseling out some chips of bone. Some space is created for a larger Coupé land to go in to further widen the socket, oozing blood helps to soften bone around the tooth.

Manipulation continued carefully until enough space is created to elevate the tooth, tooth can gradually be elevated from the point of application which is usually on the mesial side but elevation can also be done distally or buccally. If much resistance is met while elevating, then socket is not well expanded, and more space need to be created. After successful elevation of the tooth into a near erect position, it can be gently removed out of the socket with extraction forceps.

Swelling was assessed on the patients by measuring three distances with flexible calipers, the first distance was from the region of the angle of the mandible to commissure of the mouth $(\mathrm{A})$, the second was from tragus of the ear to commissure of the mouth (B), the third distance extends from outer canthus to the region of the angle of the mandible (C), all the distances assessed horizontal (anterior-posterior) dimensions of the swellings at the lower, middle and upper level respectively. The measurements were taken just before the procedure, 24 hrs and 72 hrs and 1 week postoperative. Pain was assessed by the patient at home at $3 \mathrm{hr}, 6 \mathrm{hr}, 12 \mathrm{hr}, 24 \mathrm{hr}$ and 3 day and 1 week interval using the visual analogue scale which ranges from 0 - 10 where 0 represents no pain and 10 represents the most severe pain. Comparison of pain and swelling in the two techniques was assessed with Chi-square and p value less than 0.01 was considered significant.

\section{RESULTS}

Ten patients qualified for inclusion in the study out of which 3 (30\%) were males and 7 (70\%) were females. Age range was 27 - 35 yrs. All patients had similar type of impacted mandibular third molar teeth bilaterally. Three of the patients in the first group suffered from mesio-angular impacted third molar teeth, 1 suffered from vertically impacted third molar teeth, and 1 suffered from horizontal impacted third molar teeth. In the second group, one patient each suffered from mesio-angular, vertical and horizontal impacted third molar teeth respectively. The first control suffered from horizontal impacted and the second control suffered from mesio-angular impacted third molar teeth. Of all the 10 patients, only the first control suffered from completely buried impacted third molar teeth within alveolar bone and also suffered from impacted third molar teeth buried against the second molars. The morphology of the roots in all the patients was favourable.

Out of the eight patients that had the two different techniques done on either side, 7 preferred the use of the alveolar expansion technique.

The average preoperative measurements were 9.8, 11.2 and $10.7 \mathrm{~cm}$ respectively for both sides of the face in the first group of patients who had drill used on the right side. For the second group, the average values were 9.3, 11 and $10.2 \mathrm{~cm}$ for both sides respectively who had drill used on the left side, while the controls had 10.0, 11.0 and $10.5 \mathrm{~cm}$ for the case with drill on both sides and 9.5, 10.5 and $10.0 \mathrm{~cm}$ for the case without drill on both sides. 
The 24-hour average values for the first group were 10.7, 12.0 and $11.2 \mathrm{~cm}$ on the right side and 10.6, 11.7 and $11.0 \mathrm{~cm}$ on the left side. For the second group, the values were 9.7, 11.0 and $10.1 \mathrm{~cm}$ on the right and 10.2 , 11.1 and $11.4 \mathrm{~cm}$ on the left. The two controls had closely similar 24-hour values on both sides. The 72-hour value for each patient is shown in (Tables 1-3). The 1-week average values for patients in first group were $10.1,11.5$ and $10.9 \mathrm{~cm}$ on the right and 10.1, 11.2 and $10.8 \mathrm{~cm}$ on the left. The 1-week average values for patients in second group were $9.5,11.0$ and $10.1 \mathrm{~cm}$ on the right and 9.8, 11.0 and $10.5 \mathrm{~cm}$ on the left. There were statistically significant differences in swellings between these two techniques, $(\mathrm{p}<0.01)$.The 1 -week values for the controls are shown in (Table 3).

The post operative pain rating of patients in the first group is shown in (Table 4). The ratings were higher on the right side in four of the patients but in all the patients, there was decrease pain severity at every interval. Pain ratings were higher on the left side in all the patients in the second group and also there was decrease in pain severity at intervals (Table 5). There were no statistically significant differences in pain between these two techniques, $(p>0.01)$.Pain severity was slightly higher in the control that had drill used compared to the other control. The values for the two sides in both controls were almost similar (Table 6).

\section{DISCUSSION}

Many techniques have been used to remove impacted third molar and, surgical techniques include buccal guttering, lingual split, lateral trepanation, tooth division and coronectomy [1-8]. Other techniques like therapeutic agenesis of the tooth bud using electrocautery, laser energy and use of sclerosing agents have been tried in lower mammals and animals but no human clinical studies are available to attest the validity of these later techniques [9]. Absi and sherpherd [10] have compared the lingual split technique and buccal guttering technique and they provided no evidence of difference in either efficiency or outcome between the two standard methods of removing lower third molars [10]. Our study has evaluated an alveolar expansion technique and we found that majority of patients except

Table 1. Post-operative swelling ratings in first group.

\begin{tabular}{|c|c|c|c|c|c|c|c|c|c|c|c|c|c|c|c|}
\hline \multirow[t]{3}{*}{ S/no. } & \multirow[t]{3}{*}{ Gender } & \multirow[t]{3}{*}{ Age } & \multirow[t]{3}{*}{ Side } & \multicolumn{3}{|c|}{ Pre-operative/cm } & \multicolumn{9}{|c|}{ Post-operative/cm } \\
\hline & & & & \multirow[b]{2}{*}{ A } & \multirow[b]{2}{*}{$\mathrm{B}$} & \multirow[b]{2}{*}{$\mathrm{C}$} & \multicolumn{3}{|c|}{$24 \mathrm{hrs}$} & \multicolumn{3}{|c|}{72 hrs } & \multicolumn{3}{|c|}{1 week } \\
\hline & & & & & & & A & B & $\mathrm{C}$ & A & B & $\mathrm{C}$ & A & B & $\mathrm{C}$ \\
\hline \multirow{2}{*}{1.} & \multirow{2}{*}{ M } & \multirow{2}{*}{26} & Rt & 9.5 & 11.0 & 10.0 & 12.0 & 13.0 & 11.0 & 11.5 & 12.0 & 10.0 & 10.5 & 11.5 & 10.5 \\
\hline & & & $\mathrm{Lt}$ & 9.5 & 11.0 & 10.0 & 11.0 & 12.0 & 11.0 & 11.0 & 11.0 & 10.0 & 10.0 & 11.0 & 10.0 \\
\hline \multirow{2}{*}{2.} & \multirow{2}{*}{$\mathrm{F}$} & \multirow{2}{*}{30} & Rt & 10.0 & 12.0 & 11.0 & 11.0 & 12.5 & 11.5 & 11.0 & 12.5 & 11.0 & 10.5 & 12.5 & 11.0 \\
\hline & & & $\mathrm{Lt}$ & 10.0 & 12.0 & 11.0 & 11.5 & 12.0 & 11.0 & 11.0 & 12.0 & 11.0 & 10.5 & 11.5 & 11.0 \\
\hline \multirow{2}{*}{3.} & \multirow{2}{*}{$\mathrm{F}$} & \multirow{2}{*}{28} & Rt & 9.5 & 11.0 & 11.0 & 10.0 & 11.5 & 11.0 & 10.5 & 11.5 & 11.0 & 9.5 & 11.0 & 11.0 \\
\hline & & & $\mathrm{Lt}$ & 9.5 & 11.0 & 11.0 & 9.5 & 11.0 & 11.0 & 9.5 & 11.0 & 11.0 & 9.5 & 11.0 & 11.0 \\
\hline \multirow{2}{*}{4.} & \multirow{2}{*}{$\mathrm{F}$} & \multirow{2}{*}{29} & Rt & 10.0 & 11.0 & 10.5 & 10.0 & 12.0 & 10.5 & 10.0 & 11.5 & 10.5 & 10.0 & 11.0 & 10.5 \\
\hline & & & $\mathrm{Lt}$ & 10.0 & 11.0 & 10.5 & 10.0 & 11.5 & 10.5 & 10.0 & 11.2 & 10.5 & 10.0 & 11.0 & 10.5 \\
\hline \multirow{2}{*}{5.} & \multirow{2}{*}{$\mathrm{F}$} & \multirow{2}{*}{35} & $\mathrm{Rt}$ & 10.0 & 11.0 & 11.0 & 10.5 & 12.0 & 12.0 & 10.0 & 11.5 & 12.0 & 10.0 & 11.5 & 11.5 \\
\hline & & & $\mathrm{Lt}$ & 10.0 & 11.0 & 11.0 & 11.0 & 12.0 & 11.5 & 10.0 & 12.0 & 11.5 & 10.0 & 11.5 & 11.5 \\
\hline
\end{tabular}

Rt-right, Lt-left, M-Male, F-Female.

Table 2. Post-operative swelling ratings in second group.

\begin{tabular}{|c|c|c|c|c|c|c|c|c|c|c|c|c|c|c|c|}
\hline \multirow[t]{3}{*}{ S/no. } & \multirow[t]{3}{*}{ Gender } & \multirow[t]{3}{*}{ Age } & \multirow[t]{3}{*}{ Side } & \multicolumn{3}{|c|}{ Pre-operative/cm } & \multicolumn{9}{|c|}{ Post-operative/cm } \\
\hline & & & & \multirow[b]{2}{*}{ A } & \multirow[b]{2}{*}{ B } & \multirow[b]{2}{*}{$\mathrm{C}$} & \multicolumn{3}{|c|}{$24 \mathrm{hrs}$} & \multicolumn{2}{|c|}{$72 \mathrm{hrs}$} & \multicolumn{3}{|c|}{1 week } & \multirow[b]{2}{*}{$\mathrm{C}$} \\
\hline & & & & & & & A & B & C & A & B & $\mathrm{C}$ & A & $\mathrm{B}$ & \\
\hline \multirow[t]{2}{*}{1.} & $\mathrm{~F}$ & 28 & $\mathrm{Rt}$ & 8.5 & 10.5 & 10.0 & 8.6 & 10.5 & 10.2 & 8.6 & 10.5 & 10.2 & 8.5 & 10.5 & 10.2 \\
\hline & & & $\mathrm{Lt}$ & 8.5 & 10.5 & 10.0 & 9.2 & 10.7 & 11.2 & 9.0 & 10.7 & 10.8 & 9.0 & 10.6 & 10.5 \\
\hline \multirow[t]{2}{*}{2.} & $\mathrm{~F}$ & 27 & Rt & 10.0 & 11.0 & 9.5 & 10.0 & 11.0 & 9.5 & 10.0 & 11.0 & 9.5 & 10.0 & 11.0 & 9.5 \\
\hline & & & $\mathrm{Lt}$ & 10.0 & 11.0 & 9.5 & 11.0 & 11.2 & 12.0 & 10.5 & 11.1 & 11.0 & 10.5 & 11.0 & 10.0 \\
\hline \multirow[t]{2}{*}{3.} & $\mathrm{M}$ & 29 & $\mathrm{Rt}$ & 9.5 & 11.5 & 11.0 & 10.5 & 11.5 & 10.5 & 10.5 & 11.5 & 10.5 & 10.0 & 11.5 & 10.5 \\
\hline & & & $\mathrm{Lt}$ & 9.5 & 11.5 & 11.0 & 10.5 & 11.5 & 11.0 & 10.5 & 11.5 & 11.0 & 10.0 & 11.5 & 11.0 \\
\hline
\end{tabular}


Table 3. Post-operative swelling ratings in the controls.

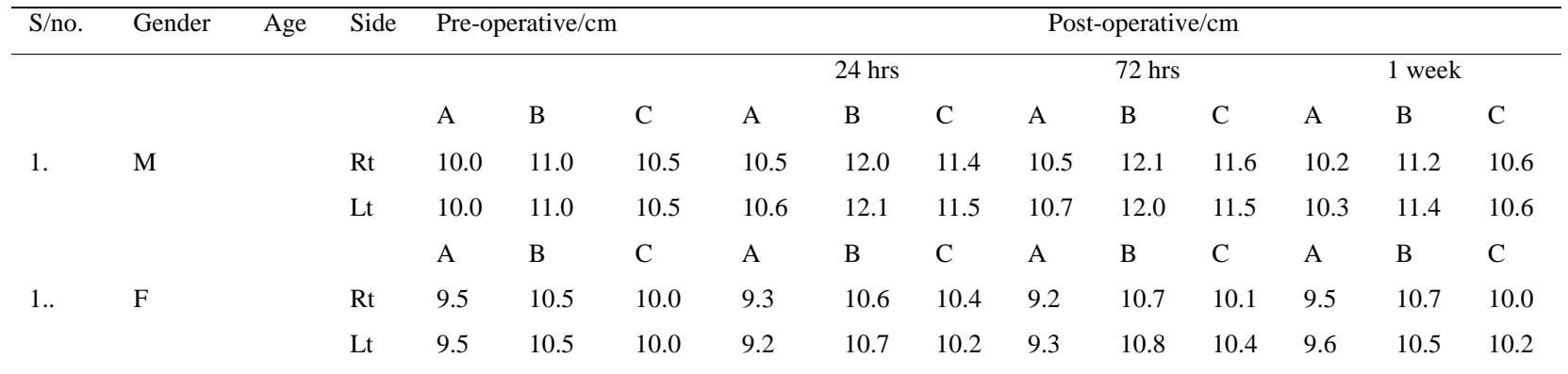

Table 4. Post-operative pain ratings in first group.

\begin{tabular}{|c|c|c|c|c|c|c|c|c|}
\hline \multirow[t]{2}{*}{ S/no. } & \multirow[t]{2}{*}{ Side } & \multicolumn{7}{|c|}{ Post-operative pain Rating } \\
\hline & & $3 \mathrm{hrs}$ & 6 hrs & $12 \mathrm{hrs}$ & $24 \mathrm{hrs}$ & $48 \mathrm{hrs}$ & 72 hrs & $1 \mathrm{wk}$ \\
\hline 1. & $\begin{array}{l}\mathrm{Rt} \\
\mathrm{Lt}\end{array}$ & $\begin{array}{l}6 \\
5\end{array}$ & $\begin{array}{l}6 \\
5\end{array}$ & $\begin{array}{l}5 \\
4\end{array}$ & $\begin{array}{l}5 \\
4\end{array}$ & $\begin{array}{l}4 \\
2\end{array}$ & $\begin{array}{l}3 \\
2\end{array}$ & $\begin{array}{l}1 \\
0\end{array}$ \\
\hline 2. & $\begin{array}{l}\text { Rt } \\
\text { Lt }\end{array}$ & $\begin{array}{l}8 \\
6\end{array}$ & $\begin{array}{l}7 \\
5\end{array}$ & $\begin{array}{l}7 \\
5\end{array}$ & $\begin{array}{l}6 \\
4\end{array}$ & $\begin{array}{l}5 \\
3\end{array}$ & $\begin{array}{l}4 \\
2\end{array}$ & $\begin{array}{l}2 \\
1\end{array}$ \\
\hline 3. & $\begin{array}{l}\mathrm{Rt} \\
\mathrm{Lt}\end{array}$ & $\begin{array}{l}7 \\
5\end{array}$ & $\begin{array}{l}7 \\
5\end{array}$ & $\begin{array}{l}6 \\
4\end{array}$ & $\begin{array}{l}6 \\
3\end{array}$ & $\begin{array}{l}6 \\
3\end{array}$ & $\begin{array}{l}5 \\
2\end{array}$ & $\begin{array}{l}2 \\
1\end{array}$ \\
\hline 4. & $\begin{array}{l}\text { Rt } \\
\mathrm{Lt}\end{array}$ & $\begin{array}{l}8 \\
5\end{array}$ & $\begin{array}{l}7 \\
4\end{array}$ & $\begin{array}{l}6 \\
3\end{array}$ & $\begin{array}{l}5 \\
2\end{array}$ & $\begin{array}{l}5 \\
2\end{array}$ & $\begin{array}{l}4 \\
1\end{array}$ & $\begin{array}{l}2 \\
1\end{array}$ \\
\hline 5. & $\begin{array}{l}\mathrm{Rt} \\
\mathrm{Lt}\end{array}$ & $\begin{array}{l}7 \\
9\end{array}$ & $\begin{array}{l}6 \\
8\end{array}$ & $\begin{array}{l}6 \\
8\end{array}$ & $\begin{array}{l}5 \\
7\end{array}$ & $\begin{array}{l}4 \\
6\end{array}$ & $\begin{array}{l}3 \\
4\end{array}$ & $\begin{array}{l}2 \\
3\end{array}$ \\
\hline
\end{tabular}

Table 5. Post-operative pain ratings in second group.

\begin{tabular}{|c|c|c|c|c|c|c|c|c|}
\hline \multirow[t]{2}{*}{ S/no. } & \multirow[t]{2}{*}{ Side } & \multicolumn{7}{|c|}{ Post-operative pain Rating } \\
\hline & & $3 \mathrm{hrs}$ & $6 \mathrm{hrs}$ & $12 \mathrm{hrs}$ & $24 \mathrm{hrs}$ & $48 \mathrm{hrs}$ & $72 \mathrm{hrs}$ & $1 \mathrm{wk}$ \\
\hline \multirow{2}{*}{1.} & Rt & 7 & 6 & 5 & 5 & 4 & 3 & 1 \\
\hline & $\mathrm{Lt}$ & 9 & 8 & 7 & 7 & 6 & 4 & 2 \\
\hline \multirow{2}{*}{2.} & Rt & 6 & 5 & 5 & 4 & 4 & 3 & 2 \\
\hline & $\mathrm{Lt}$ & 8 & 7 & 6 & 6 & 5 & 4 & 3 \\
\hline \multirow{2}{*}{3.} & Rt & 8 & 8 & 6 & 4 & 3 & 2 & 1 \\
\hline & $\mathrm{Lt}$ & 9 & 9 & 7 & 5 & 4 & 3 & 2 \\
\hline
\end{tabular}

Table 6. Post-operative pain ratings in the controls.

\begin{tabular}{|c|c|c|c|c|c|c|c|c|}
\hline \multirow[t]{2}{*}{ S/no. } & \multirow[t]{2}{*}{ Side } & \multicolumn{7}{|c|}{ Post-operative pain Rating } \\
\hline & & $3 \mathrm{hrs}$ & $6 \mathrm{hrs}$ & $12 \mathrm{hrs}$ & 24 hrs & $48 \mathrm{hrs}$ & $72 \mathrm{hrs}$ & $1 \mathrm{wk}$ \\
\hline \multirow{3}{*}{1.} & Rt & 7 & 7 & 6 & 3 & 3 & 2 & 2 \\
\hline & $\mathrm{Lt}$ & 7 & 7 & 6 & 4 & 3 & 3 & 3 \\
\hline & & $3 \mathrm{hrs}$ & $6 \mathrm{hrs}$ & $12 \mathrm{hrs}$ & $24 \mathrm{hrs}$ & $48 \mathrm{hrs}$ & $72 \mathrm{hrs}$ & $1 \mathrm{wk}$ \\
\hline \multirow{2}{*}{1.} & Rt & 7 & 6 & 5 & 3 & 2 & 3 & 1 \\
\hline & Lt & 7 & 6 & 4 & 3 & 2 & 2 & 1 \\
\hline
\end{tabular}

few with low pain threshold would like to avoid use of drills when possible because of the vibrations and friction.

Friedman [1] debated on the issue of prophylactic and theraupetic surgical extraction of lower third molar. They documented the five myths associated with lower third molars and from the point of view of public health concluded that prophylactic is not justified. They also 
reported that complications like dry socket, secondary infection and paraesthesia associated with lower third molar extraction are more in the 25 - 34 years age group rather than the 12 - 24 years and 35 - 83 years age group. However, surgical extraction without drills for indicated third molars could be achievable in some patients in any of these age groups. The consideration of any technique should not only be effectiveness and ease in removal of the tooth but also the reduction in post-operative morbidities like pain and swelling which were more in the buccal guttering technique. Complications like dry socket and fractures of the mandible are more in lingual split technique and, occasionally in buccal guttering technique especially in patients with brittle bones when a lot of bone is removed [1,5,6,10,11].

Garcia et al. [11] also reported that pain and trismus were less with the use of only forceps, for extraction than cases in which surgical extraction were done with ostectomy, with or without coronal section and other complex procedures. They found that trismus severity after surgical extraction does not depend on difficulty of surgery and pain, as revealed by reported analgesic use, and likewise less severe after simple extractions [11]. Our study did not assess trismus because both sides were done consecutively on same day and the differences in the two techniques on trismus will not be easily appreciated. Also in the study of Garcia et al, regardless of extraction type, pain declines between days 1 and 5 after surgery [11]. Findings in our study with respect to pain and swelling reduction in the simpler procedure and with periodic interval were similar to that of other reports [12-15]. Spinal/supraspinal modulation which is peculiar and variable in different patients, as well as analgesic control of pain altered the significance of difference in pain severity in the two techniques. However, our findings still reflect that sides with larger swellings still produce higher levels of pain. The swellings are inflammatory responses to the incisions and reflections of mucoperiosteum as well as crushing injury to the lamella and trabeculae bone surrounding the tooth. Despite the fact that standard surgical precautions were followed in both techniques in our study, it was found that swellings were more in the buccal guttering technique due to extensive reflections and drillings of bone.

The alveolar expansion technique is however, better applicable in younger patients with less dense bone, patients with soft tissue impacted third molar, vertically or mesially impacted tooth with sufficient space for the elevator to move the tooth into, when there is no impaction against the second molars and in cases of close proximity of the neurovascular bundle with enough clearance around the tooth. Absolute contraindications of the use of this technique include high bone density, com- pletely buried tooth/tooth with high Winter's red line, horizontal impaction associated with impaction against the second molar, distal or vertical impaction with part of the tooth buried under the ascending ramus, anteriorly extended external oblique ridge and in patients with very low pain threshold.

\section{CONCLUSIONS}

To avoid excessive swelling and pain from overambitious cutting of soft tissues and drilling of bone, alveolar expansion technique should be considered first in patients with less dense bone, close root/tooth related neurovascular bundle, mesial or vertical with crown level close to the occlusal level. Therefore, careful patient selection and effective blockage of the nerves must be the points of consideration to achieve success.

\section{REFERENCES}

[1] Friedman, J.W. (2007) The prophylactic extraction of third molars: A public health hazard. American Journal of Public Health, 97, 1554-1559. doi:10.2105/AJPH.2006.100271

[2] Güven, O., Keskin, A. and Akal, U. K. (2000) The incidence of cysts and tumors around impacted third molars. International Journal of Oral and Maxillofacial Surgery, 29, 131-135.

[3] Gülicher, D. and Gerlach, K.L. (2001) Sensory impairment of the lingual and inferior alveolar nerves following removal of impacted mandibular third molars. International Journal of Oral and Maxillofacial Surgery, 30, 306-312. doi:10.1054/ijom.2001.0057

[4] Hupp, J. R. (2006) Contemporary oral and maxillofacial surgery. 5th Edition, Mosby Johnson.

[5] Sisk, A.L., Hammer, W.B., Shelton, et al. (1987) Complications following removal of impacted third molar. The role of the experience of the surgeon. Journal of Oral and Maxillofacial Surgery, 45, 906.

doi:10.1016/0278-2391(87)90437-X

[6] Garcia-Garcia, A. (2005) Coronectomy: A questionable procedure. Letter to the editor. Journal of Oral and Maxillofacial Surgery, 63, 723.

[7] Benediktsdóttir, I.S., Wenzel, A., Peterson, J.K., et al. (2004) Mandibular third molar removal: Risk indicators for extended operation time, post operative pain, and complications. Oral Surgery, Oral Medicine, Oral Pathology, Oral Radiology and Endodontology, 97, 438446. doi:10.1016/j.tripleo.2003.10.018

[8] Garcia-Garcia, A. (2006) Is coronectomy really preferable to extraction? British Journal of Oral and Maxillofacial Surgery, 44, 75. doi:10.1016/j.bjoms.2005.02.015

[9] Rozkovcova, E., Markova, M. and Dolejsi, J. (1999) Studies on agenesis of third molars amongst populations of different origin. Sbornik Lekarsky, 100, 71-84.

[10] Absi, E.G. and Shepherd, J.P. (1993) Comparison of morbidity following the removal of lower third molars by the lingual split and surgical bur methods. International Journal of Oral and Maxillofacial Surgery, 22, 149-153.

[11] Garcia, G.A., Gude, S.F., Gandara, R.J. and Gallas, T.M. 
(1997) Trismus and pain after removal of impacted lower third molars. Journal of Oral and Maxillofacial Surgery, 55, 1223-1226.

[12] Ali, A., Cunliffe, D.R. and Watt-Smith, S.R. (2000) Surgical emphysema and pneumomediastinum complicating dental extraction. British Dental Journal, 188, 589-590.

[13] Gargallo-Albiol, J., Buenechea-Imaz, R. and Gay-Escoda, C. (2000) Lingual nerve protection during surgical removal of lower third molars. a prospective randomised study. International Journal of Oral and Maxillofacial Surgery, 29, 268-271.

doi:10.1034/j.1399-0020.2000.290407.x

[14] Peterson, L., Ellie, E., Hupp, J. and Tucker, M. (2003) Contemporary oral and maxillofacial surgery. 4th Edition, Mosby, Saint Louis.

[15] Pogrel, M.A. and Kaban, L.B. (1993) Injuries to the interior alveolar and lingual nerves. Journal of the California Dental Association, 21, 50-54. 